\title{
ETHNOCULTURAL FEATURES OF THE FRENCH ADVERTISING DISCOURSE (BASED ON FRENCH SOCIAL ADVERTISING)
}

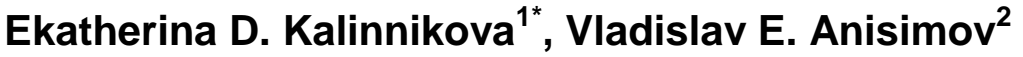 \\ ${ }^{1}$ Master student RUDN University, RUSSIA, kate.dk01@gmail.com \\ ${ }^{2}$ PhD student RUDN University, RUSSIA, anisimov_ve@rudn.university.ru \\ ${ }^{*}$ Corresponding Author
}

\begin{abstract}
The study of ethnocultural features begins playing an important role in modern education. Social advertising is a type of non-commercial advertising with the main task to draw public attention to various social problems. Social advertising can exist in the form of creolized text with the main function of suggestive influence, whose main purpose is to attract the attention of potential recipients to the social problems. The specificity of social advertising is that in each linguoculture it acquires its own forms of expression depending on the actual needs of society or the forms of their implementation in a particular environment. French national social advertising is characterized by a wide range of uses of the emotive component to create campaigns. Thus, the main specificity that characterizes linguistic culture will be the subject and methods of their representation. The object of this paper is the examples French street social advertising (placed on billboards in public places, in the form of text advertising, etc.) and highlighted two series of features that will characterize national specificity of discourse: means of emotive and lexical transmission. In the course of the study, we have analysed 30 objects of modern French street social advertising related to various social problems. The methods of discourse and content-analysis were used for the research. To indicate the periodic framework, we reviewed the material posted over the past 3 years (January 2017-January 2020). The use of this set of methods allowed us to identify the ethnocultural features of the representation of social advertising texts in the French advertising discourse. As a result of the study, we conclude that this type of advertising text has nationally specific features. So, based on the analysis, we have identified that street social advertising itself tends to be laconic, problematic in content, as well as a high degree of emotive expressiveness. Among the cultural manifestations of the specific features of emotivity in street texts of social advertising in France, we highlight the following features of the representation of emotive : creativisation process of making social advertising (creolized) texts and their accompanying visual series through the use of metaphors, puns, techniques of intertextuality to achieve intensification effect. Visuals in social advertising texts are often used as an auxiliary or main (as in the case of non-textual advertising) semantic component, which indicates the creolized and sometimes polycode nature of the discourse. The results obtained in this research can be successfully used in study of French national specificity in case of global High school education.
\end{abstract}

Keywords: advertising discourse, social advertising, emotivity, ethnocultural features, education.

\section{INTRODUCTION}

The problem of discourse emotivity is one of the new challenges of our time. The influence of emotions on text and communication has been studied in linguistic science relatively recently due to the beginning of the formation of psycholinguistic aspects of language learning. The text in the study refers to the result of human 
language activity (both oral and written).

The concept of emotivity is a linguistic category that reflects the phenomenon of mental emotionality. However, emotivity itself is an immanent property of language which helps reflect the mental state of a person in the text.

\section{THEORETICAL APPROACHES OF ETHNOCULTURAL AND EMOTIVE FEATURES IN THE FRENCH ADVERTISING DISCOURSE}

The problem of text emotivity was developed in the works of lot Russian linguists, such as Bydina (Bydina, 1994), Lenko (Len`ko, 2014), Arnold (Arnold, 1991), Shakhovsky (Shahovsky, 2004), etc. The important role in the theories of discourse emotivity formation is played by an Australian researcher of Soviet origin Anna Wierzbicka (Wierzbicka, 2014).

Another relevant aspect of the study is the linguistic and cultural specificity of the emotivity manifestation in the text and discourse. In this paper, we will consider discourse as a verbally articulated form of the subject's consciousness representation, which is formed under the influence of a specific socio - and linguistic-cultural tradition of the society or industry in question (Shahovsky 2004). At the same time, we also fully accept that the qualitative characteristics of discourse are integrity and contextuality (Leech, Larina 2014). Contextuality, in turn, is understood as the situational application of texts in the area under consideration, depending on external and internal factors, such as: the communicative situation of interaction, the subjects of communication, the object of representation, the emotive and evaluative characteristics of the text, etc. Discourse is a coherent sequence of text and context, which determines its linguistic category. The national specificity of the emotive texts were extensively explored in Brown and Levinson, Hofstede, Lich (Benveriste 1993) works as a part of the national specific of courtesy studies. Tatiana Larina (Larina, Alba-Juez, 2018), Svetlana Ivanova (Ivanova, Chanysheva, 2014), and Laura Alba-Juez (Alba-Juez, 2016) have studied directly the theory of discourse emotivity and its national specificity.

Features of the emotivity manifestation in a special discourse (e.g. advertising discourse) represent a waste area of recent research, where there is no single view on the pragmatics of emotions (Blanche, 1989). Thus, the study of the peculiarities of the emotivity manifestation in the French-language advertising discourse is a research on the interfaces between two schools of the pragmatics of emotions analysis: linguistic and cultural specificity and special (advertising) discourse characteristics (Borisova, Naydenova, 2013).

(Proceeding from the idea of the phenomenon of social advertising is a type of non-commercial advertising, which main purpose is to attract public attention to various social problems. Social advertising can exist in the form of creolized text with the main function of suggestive influence. The specificity of social advertising is that in each linguistic culture it acquires its own forms of expression, depending on the actual needs of society or the forms of their implementation in a particular environment.

French national social advertising includes a wide range of emotive component use to create promotional campaigns. The main specificities that characterizes linguoculture are the subjects and their linguistic representation methods (Firsova, Borissova, 2011). Thus, the problems of violence, tolerance, road safety and public transport, measures of social support for the population, problems of poverty and unemployment, as well as issues of addiction (mainly toxic: drug addiction, alcoholism, smoking) represent the main subjects of French social advestising.

\section{RESEARCH MATERIAL}

In this study, we examine French street social advertising (placed on billboards in public places, in the form of text advertising, etc.) and single out two sets of features that characterizes the French social advertising national specifics: means of emotional and lexical transmission. The research material includes 30 objects of modern French street social advertising factually based on various social problems. The paper uses methods of discourse and content analysis. All the texts under consideration are examples of national French social advertising, and not objects of localization. Also, all corpus texts directed non-commercial in nature. To indicate the periodic framework, we reviewed the material posted over the past 3 years (January 2017-January 2020).

\section{RESULTS OF THE RESEARCH}

In the first stage of the study, we focus on the lexical ways of expressing emotivity in the texts under consideration. For structuring, slogans will be considered according to the stated subjects: 1) violence; 2) road safety; 3) safety in public transport; 4) poverty and unemployment; 5) addictions; 6) tolerance. 
Our aim is to analyse the advertising slogans and visual range, respectively, for some of the declared sections.

The problem of violence is extremely relevant for modern France: violence against women, children and domestic violence. One of example representing this social problem in French social advertising is the slogan: Violences conjugales. Se taire c'est participer ('Domestic violence. To be silent is to participate'). Here we can note the use of elliptical and unfinished structures, which at the emotional level deepens the overall emotional message of advertising: oppression, pain, and indifference of others. It is also possible to note the use of verb reflexive forms, which allows one to create the impression of belonging, and the application of the infinitive emphasizes the generalization of the stated problem.

The next analised French social advertising subject is problem of tolerance in society. In accordance with the EU migration policy, France, among many countries, has received a large flow of migrants in recent years, some of whom have become citizens of the state. In this regard, the problem of tolerance in society has been updated. This issue is particularly acute with regard to Muslim migrants, who currently make up a quarter of the France population.

However, problems of tolerance also relate to issues of mixed marriages, homosexuality and many other problems of modern developed countries.

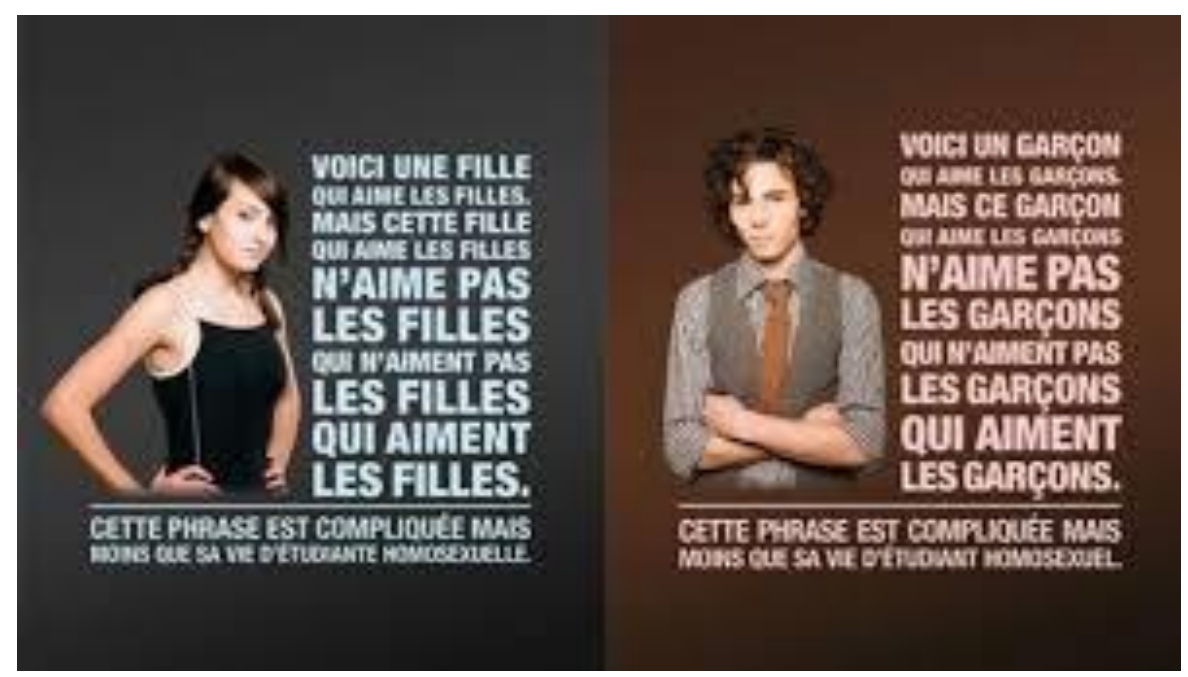

In this ad text, we can observe the absence of the slogan as an advertising object. Instead, the short text form is used: Voici un garçon qui aime les garçons. Mais ce garçon qui aime les garçons n'aime pas les garçons qui n'aiment pas les garçons qui aiment les garçons. Cette phrase est compliquée, mais moins que la vie d'étudiant homosexual ('Here is a boy who loves boys. But this boy who likes boys doesn't like boys who don't like boys who like boys. This sentence is complicated, but less than the life of a homosexual student'). Using a complex structure and the homosexuality concept mentioning it in the text sets the emotivity of this ad at the level of a global and " complex for society " problem. So, here at the lexical level, we can note the multiple use of repetitions, the use of circulative constructions (the end of a thought again leads to the beginning of the next one, creating a circle). The tagline is the final sentence below the line. The line acts as a graphic indicator of emotivity serving to emphasize and/or strike out. We can also see the use of the emotive-strong verb aimer ('to love'), to actualize the connotations of universal, global values within a particular issue.

Next, we will consider the topic of behavior culture in public transport. The culture of behavior in public places, especially in public transport, represent an urgent problem for France. In this regard, ads were placed in major cities that normalize the behavior of citizens in public areas. 


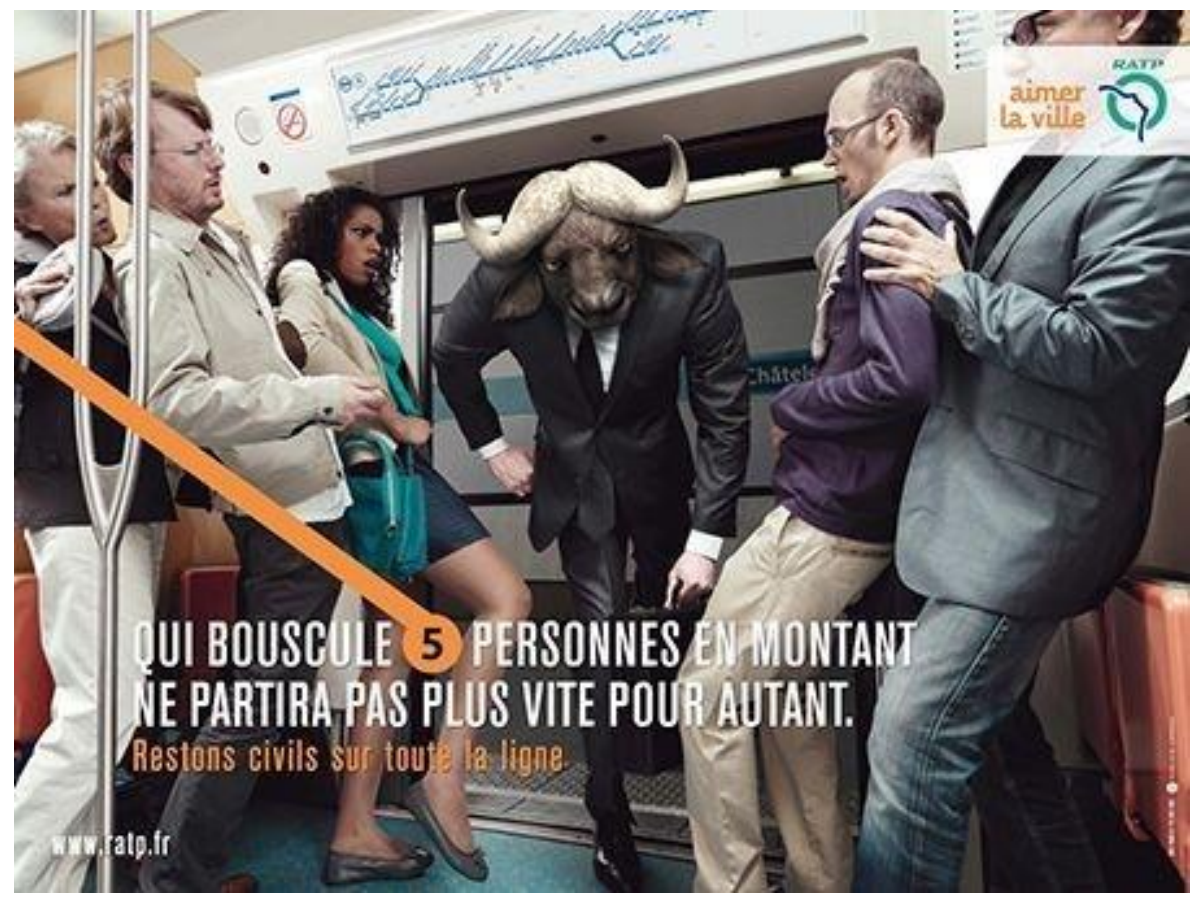

Image A.

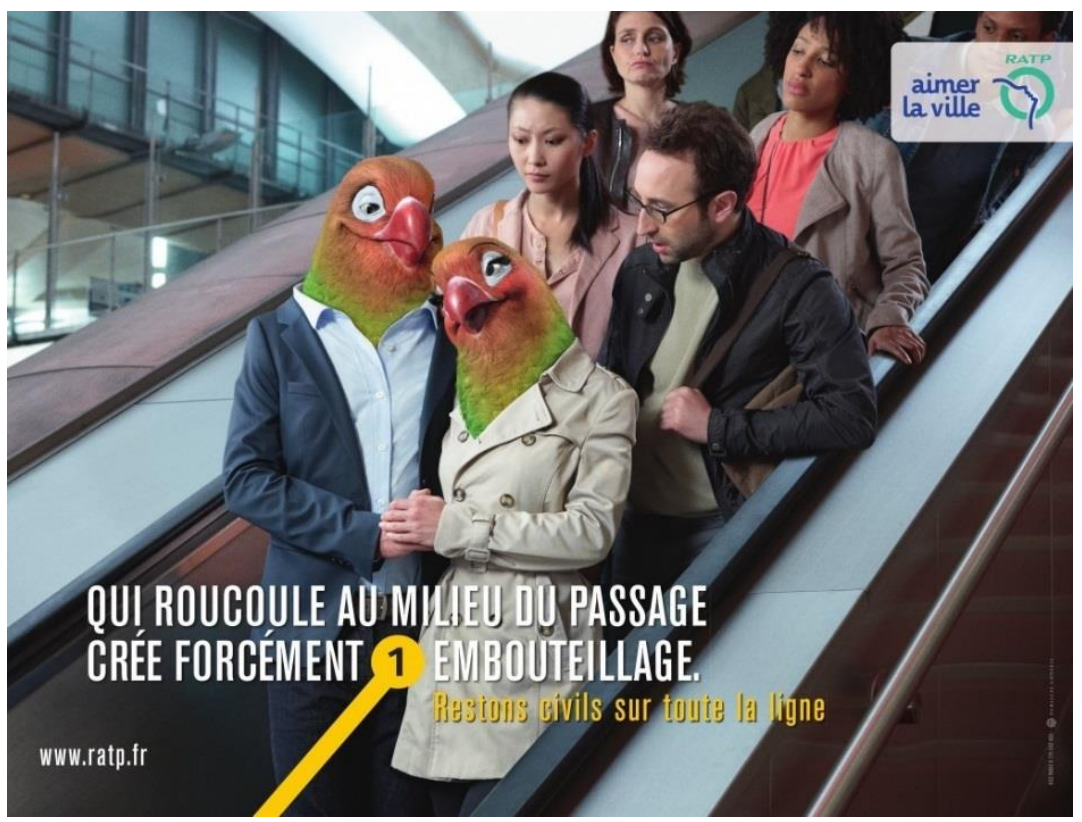

Image B.

A striking example of this kind of advertisement is the billboards used in the French metro: Qui bouscule 5 personnes en montant ne partira pas plus vite pour autant. Restons civils sur toute la ligne.(A, 'Who upsets 5 people on the way up will not leave any faster. Let us remain civilians all along the line') Qui roucoule au milieu du passage crée forcement 1 emboutellage. Restons civils sur toute la ligne. (B, 'Who cooed in the middle of the passage necessarily creats 1 emboutellage. Let's stay civil for the line'). This ad example includes the short main text and the final slogan as well, which will be common for the entire series of this advertising campaign. First, let's look at the text. The form of the text representation is a rhymed couplet aimed at attract recipients' attention. It should be noted the use of full design, index design Qui.. ('Who'), as well as the simple verbal forms of the present and the future time that allows one to focus emotively on the current moment. However, it is also interesting the using of animalistic forms: bousculer, roucouler ('upset,

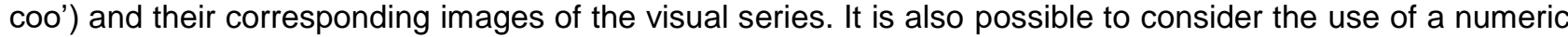
series with color markings as an intertext in view of its corresponding to the metro line color where the ad is placed. 
This kind of social advertising slogan is contained in the final part of the sentence. It is made in the form of a personal imperative 1 person plural, which should simultaneously cause the effect of transfer and normativity of the 'given' rules.

The final part of our research connected with the subject of unemployment and poverty, which is particularly relevant for France during the current crisis.

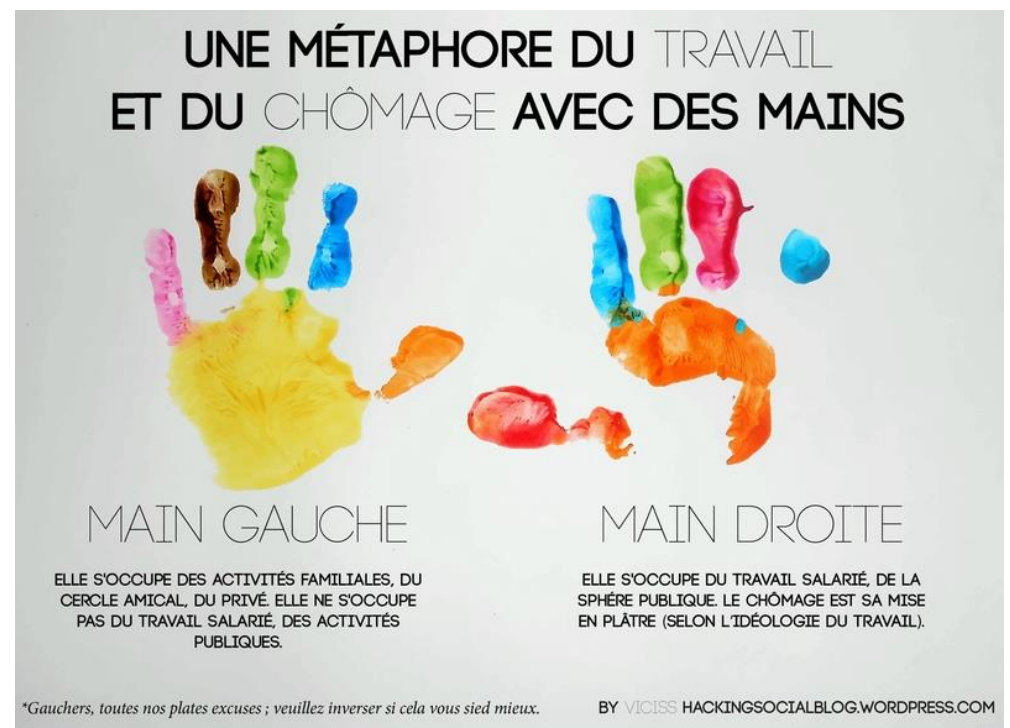

This ad, unlike all the ones presented, consists of a title and text, without a slogan:

Une metaphore du travail et du chomage avec des mains ('A metaphor of work and unemployment with hands')

Main gauche (Left hand)

Elle s'occupe des activites, du cercle amical, du prive. Elle ne s'occupe pas du travail salarié, des activites publiques ('She takes care of the activities, the friendly circle, the private. She is not concerned with paid work, public activities')

\section{Main droite (Right hand)}

Elle s'occupe du travail salarié, de la sphere publique. Le chomage est sa mise en platre (selon lideologie $d u$ travail) ('She is in charge of salaried work, of the public sphere. Unemployment is its setting in plaster (according to the ideology of work').

Here we deal with the text that will be marked as a description of the visual image. The ad shows two hands painted in bright colors, while the palm prints are different. The description of these differences is contained in the text, although the unifying metaphor is color as an emotive compatibility of society. The seme of togetherness can be considered both in the direct meaning of common work and common efforts, as well as the solidarity of society. The form of advertising representation resembles a parable, which is supported by the format of the hands personification as a phenomenon of animism.

\section{CONCLUSION}

The results of the research brings us to the following conclusion. In the context of advertising discourse, especially within social advertising and advertising slogans, French lexemes have more abstract and, accordingly, a large semantic field, which can be realized including emotic seme that generates more conceptual. However, lexemes are not characterized by frequency semantic agreement. On the contrary, there is often a animism or personification, when an inanimate thing performs the role of an animate subject. In French, expressiveness and its associated emotivity are realized more towards metaphorical and stylistic functions. We can also note the paradigmatic economy of French slogans, when the idiomatic and stylistic load on the lexeme is reduced, but without loosing its emotional content. It is also possible to note the national-specific of the substance of French texts.

Another specifics of the national French advertising discourse is the national focus on preserving the identity of the French language itself, including within the framework of special discursive practices. The results of 
our research revealed that the social advertising texts include national and specific features. Thus, based on the analysis, we have identified that street social advertising itself tends to be concise in its expression, problematic in its content, as well as a high degree of emotive and expressive expressiveness.

Among the culturally specific features of emotivity in street texts of social advertising in France, we distinguish the following features of emotivity representation: creativisation process of making social advertising (creolized) texts and their accompanying visual series through the use of metaphors, puns, techniques of intertextuality to achieve intensification effect. In the texts of social advertising, the visuals are often used as auxiliaries or main (as in the case of non-text advertising) semantic components, which indicates the creolized, and sometimes poly-code nature of the discourse.

The study of emotivity and national specificity is of great importance for the applied aspect of language teaching. In addition to representing the current state of the language at all levels (lexical, grammatical and stylistic), social advertising also provides extensive material for linguistic and cultural analysis and research of national specifics, which can be useful in the study of foreign language culture for students of linguistic specialties.

\section{FOUNDING/AKNOWLEGMENT}

The publication has been prepared with the support of the «RUDN University Program 5-100» (project number 056111-0-000). Authors 1 and 2 all contributed equally and should be considered co-first authors.

\section{REFERENCE LIST}

Bydina I. V. (1994) The movement of emotive semantics of the poetic word (based on the poetry of A. Voznesensky, E. Evtushenko, N. Mateeva): dissertation abstract. ... PhD. Volgograd, 18 p. (In Russ)

Len'ko G. N. (2014) Levels of analysis of text emotiveness (based on the artistic style texts) // Vestnik Leningradskogo gos. un-ta im. A. S. Pushkina. Vol. 1. № 2. pp. 192-201. (In Russ)

Arnold I.V. (1991) Fundamentals of Scientific Research in Linguistics. Moscow: High school of education, 140 p. (In Russ)

Shakhovsky V. I. (2004) Linguistic theory of emotions. Moscow, 416 p. (In Russ)

Wierzbicka A. (co-authored with Cliff Goddard) (2014). Words and Meanings: Lexical Semantics Across Domains, Languages, and Cultures. Oxford UP, 272 p.

Grunig B. (1989) Les mots de la publicite. L'architecture du slogan. Paris, CNRS Editions, 249 p.

Benveniste E. (1993). Problemes de linguistique generale / E. Benveniste.- France, Gallimard, p.242.

Larina T.V., Alba-Juez L. (2018) Language and emotion: Discourse-pragmatic perspectives // Russian Journal of Linguistics. Vol. 22, no. 3. pp. 9-37.

Ivanova S.V., Chanysheva Z.Z. (2014) Semantics and Pragmatics of a Linguistic Sign as Cultural Information Drivers // Russian Journal of Linguistics. № 4. pp. 153-164. (In Russ)

Alba-Juez, L. (2016). Discourse Analysis and Pragmatics: Their scope and relation. Russian Journal of Linguistics, Vol. 20, $n^{\circ} 4$. pp. 43-55.

Leech G., Larina T.V. (2014) Politeness: West and east // Russian Journal of Linguistics. no. 4. pp. 9-34.

Borisova A.S., Naydenova N.S. (2013) Appellative strategies in modern French printed advertising: intercultural analysis // Russian Journal of Linguistics. №2. pp. 80-88.

Firsova N.M., Borissova A.S. (2011) National precedent phenomena in French printed advertising // Russian Journal of Linguistics. №3. pp. 84-89. (In Russ) 